\title{
Medical Aspects Taken for Granted
}

\author{
Mohammad Ahad Qayyum*, Ahmad Ayaz Sabri ${ }^{*}$, Fawad Aslam ${ }^{\dagger}$
}

It is quite extraordinary how the knowledge of certain aspects of medicine such as understanding medical etymology, symbols and history are not stressed upon during our medical training. These aspects are in fact responsible for forming the basis of our identity as medical practitioners, the ignorance of which is rather unfortunate because, in my experience, I have found these topics to be extremely potent in enhancing one's understanding and interest in his/her profession.

\section{UNDERSTANDING WORDS}

We go through life calling our colleagues byattaching the word 'doctor' before their names.

'Good morning Doctor James.'

'How do you do Doctor Polish?'

What is intriguing is that despite using the word 'doctor' on a regular basis, not many people know what the word literally means in a medical context. I was well into in my final year of medical school when I came across its literal meaning.

Now the question beckons, how many of us know or have tried to find out what the word 'doctor' means? A classic example of how we take the nuts and bolts of our profession for granted. 'Doctor' actually means 'teacher or scholar' (1), thus in the sentence 'Doctor of Medicine.' Other such words include the word 'surgeon' which interestingly enough means 'handyman or manual labourer' (1). Another example is that of the prefix ' $\mathrm{Rx}^{\prime}$ while writing prescriptions. We tend to overlook that ' $\mathrm{Rx}$ ' actually means recipe. Even more fascinating is when we realize that $\mathrm{Rx}$ is derived from the astrological sign for Jupiter, which was once placed on prescriptions to invoke that God's blessing on the

\footnotetext{
*To whom correspondence should be addressed: Mohammad Ahad Qayyum, 9 - J Johar Town, Sunflower Colony, Lahore, Pakistan Tel: 92-42-5310776

E-mail: soddadoctor@hotmail.com
}

drug to help the patient recover. In a similar manner we tend to overlook the meaning of words like 'physician,' 'medic' and 'nurse' to quote a few examples.

\section{THE WHITE COAT}

During medical school, like most other students, I also wore the white doctor's overall with great pride. Surprisingly, yet again not many bother to question the objective or the white colour of the coat. And this naïve mind set is what actually concerns me.

Interestingly enough, earlier in the history of medicine, the white overall was not white at all. It was black for quite a while (2). But after realizing that black conveyed a sense of mourning and approaching death, the color was changed to beige and then finally white. The color white representing purity, is a visual reminder of the physician's commitment to do no harm. It communicates the physician's medical intent and serves as a symbolic barrier (boundary perhaps?) that maintains the professional distance between physician and patient (2). The white coat reminds physicians of their professional duties, as prescribed by Hippocrates, to lead their lives and practice their art in uprightness and honour (2). Perhaps most importantly, the white coat is a cloak of compassion (3). Other reasons include professionalism, identification, and hygiene, yet white coats may also be a source of, rather than a barrier to, cross infection (4).

It is intriguing how we wear the white coat regularly but almost never stop to think of its purpose or the reason for its colour. In a recent study conducted at Christchurch Hospital, New Zealand, patients were asked what they preferred their doctors to be wearing. Patients preferred doctors to wear semiformal attire, but the addition of a smiling face was even better. The next most preferred styles were semiformal without a smile, followed by white coat, formal suit, jeans, and casual dress (5). 


\section{THE INSIGNIA OF MEDICINE}

A similar trend exists on assessing the awareness of the insignia of medicine and the wisdom behind it. Almost every medical practitioner has seen the symbol, may it be on white overalls, books, pens, conference posters, web pages, or identification cards. Yet it seems not many people know what the symbol stands for.

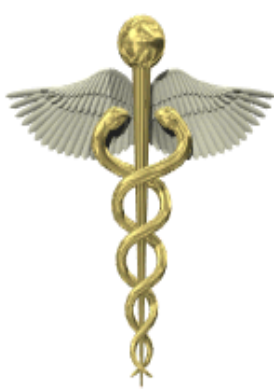

Figure 1. The Caduceus

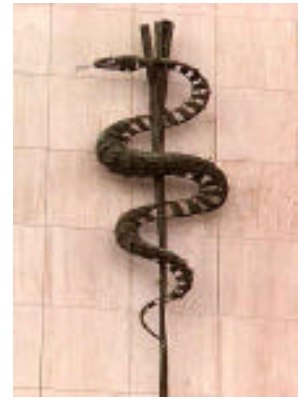

Figure 2. The Aesculapius
The symbol of our profession is the 'Aesculapius' or the 'Caduceus' (Figure 2 and 3). Either way it involves a single or two serpents (snakes) entwined around a single staff respectively (6). It really does seem a paradox how such a horrific insignia involving snakes could represent a profession dedicated to selfless patient care. One does not just wake up one day and say 'lets' make a snake around a staff and declare it our official insignia.'

Greek mythology reveals some amazing facts in this regard. It reveals that the 'Caduceus' is actually a representation of the Greek God of Commerce hence has been wrongly used all along. In reality, the logo of medicine is the Staff of Aesculapius, i.e. a single staff symbolizing the tree of life from the Garden of Eden entwined by a single serpent representing the vital forces of life, rejuvenation, wisdom and longevity. So the insignia is supposed to be a single serpent contradictory to the two serpent depiction regardless of asymmetry.

It is very interesting to note that the Staff of Aesculapius (with the single serpent) actually gained recognition in the treatment of Dracunculus medinens is also known as guinea worm. This worm would crawl under the skin of the patient and the only way to remove the worm was to slit the skin and slowly wind the worm out around a stick. As this infection was common in those days, physicians advertised this service as a serpent or worm wrapped around a stick. Furthermore this procedure required know how, patience, close attention and a delicate touch, which made it a fitting symbol of a physician's care (7).

\section{HISTORY OF MEDICINE}

History has long played a role in the education of physicians, but the uses of medicine's past have changed over time. In the late nineteenth century, some physicians taught medical history to their students to supply a sense of continuity with professional traditions in times of rapid and bewildering change. Other physicians believed that instruction in medical history would impart a sense of refinement to medical practitioners (8). Nowadays, unfortunately the general perception is to concentrate on the science of medicine and take the humanities for granted.

I believe that each practitioner should be aware of the history of the medicine he practices. To explain this further, let us take the example of the 'percussion.' With the help of percussion we determined the presence of various pathologies in the chest and abdomen by listening for the various types of notes but we seldom stop to question how Auenbrugger got the idea of striking a pleximeter placed on the human body to determine the presence of disease. Interestingly, he actually attributed his discovery to his boyhood experience watching his father tapping to define the level of fluid in kegs. He noticed the way beer brewers tapped the sides of the beer barrels to hear if they were full or empty. Applying the same principle, he was able to detect the presence of fluid in chest and abdomen (9).

By knowing things like these, not only are we exposed to a lighter side of medicine but it also enables us to think like scientists. It makes us realize how in the past people noted an effect and transformed it into a useful substance or method. Apart from this by familiarizing oneself with history, we also pay homage to the ancestors of our profession. It is noteworthy how we take such things for granted just as if they appeared out of nowhere, hence denying our professional ancestors of the credit they deserve for deducing diagnostic methodology and treatments we use so regularly.

Similarly, what about auscultation? Laennec did not just find an assembled stethoscope lying under a tree and said 'Hey! What the heck! Let us just listen in for a diastolic murmur.' Actually Laennec recognized how one can hear a pin scraping one end of a plank by putting one's ear to the other end and as a result came up with the idea for a stethoscope prototype. He rolled a stack of paper into a cylinder, pressed one end to the patient's chest, and held his ear to the other end. And so began auscultation (9).

Apart from this, other examples of ignorance on our part include the 'Hippocratic Oath.' We all took the oath but never really bothered to find out who Hippocrates was (Figure 3).

\section{CAUGHT OFFSIDE}

On the very first day of my clinical rotation our 
medical officer cried out: 'Always examine the patient from the right side'. I asked him why it was so. Unsurprisingly, 'traditions' he remarked. I have always found this mind set of accepting things as they are without any sound reasoning bizarre. Traditions are always based on some reasoning. Still we choose not to bother ourselves to look for the reasoning and take the easier way out, which is ignoring to question them at all.

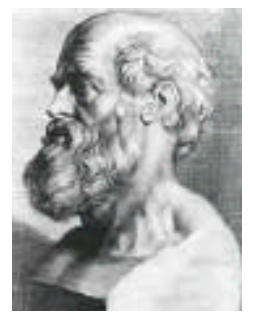

Figure 3. Hippocrates (the father of medicine). Engraving by Peter Paul Rubens, 1638. Courtesy of the National Library of Medicine.

Some people say we stand on the right as 'it gives the doctor more manoeuvrability to examine with his right hand' (10). Then, my question is: why do lefthanded people stand on the right side as well? Or has the medical profession got something against the lefthanded population now? The answer to why we always have to stand on the right side of the patient while examining him still evades me.

\section{SO WHAT'S THE POINT?}

By ignoring aspects like the ones stated above we deprive ourselves of the opportunity to understand our own identity and past as medical practitioners. Such aspects also present themselves as a lighter side of medicine which is dispossessed due to an unfortunate mind set of taking things for granted.

The point is that the complete understanding of one's profession is imperative to groom a well rounded professional. Clearly, in case of medicine, practitioners have a tendency to avoid the humanitie, and as a result have little background knowledge about the origins and traditions of our great profession. Thus limiting the magnetism of our career. Why is it that we do not question our traditions, origins and methodology? Are we scared or are we just not bothered? The white coat, the insignia, examining patient from the right, and the tendency to avoid our history are just a handful of examples. The understanding of medical humanities provides doctors with an opportunity to view the practice of medicine at a time when things like X-rays, $\mathrm{CBCs}$ and MRIs were not present. It provides inspiration to doctors as well help them understand the nature of our shared humanity (11).

Doctors are generally experts in the art of delayed gratification and self-neglect (12) and bad at avoiding burnout (13). The understanding and study of medical traditions can play a role of a stress reliever and provide the practitioner with a more mature outlook. After all, broad range of interests and an encompassing worldview make for emotional and physical wellbeing (14).

To achieve such an effect, such aspects of medicine should be incorporated within the medical curriculum at both undergraduate and postgraduate levels. Dispensing of such education will help medical students understand the scientific and humanistic character of medicine.

\section{REFERENCES}

1. Webster's New World ${ }^{\mathrm{TM}}$ Medical Dictionary. 2nd Ed. Wiley Publishing, 2003.

2. Jones VA. The White Coat: Why not follow suit? JAMA 1999; 281:478.

3. Lewis LD. White Coat Ceremony Keynote Address. Presented at: Columbia University College of Physicians and Surgeons; August 26, 1994; New York, NY.

4. Wong D, Nye K, Hollis P. Microbial Flora on Doctors' White Coats. BMJ 1991; 303: 1602-4.

5. Lill MM, Wilkinson TJ. Judging a Book by Its cover: Descriptive survey of patients' preferences for doctors' appearance and mode of dress. BMJ 2005;331:1524-1527.

6. Wilcox RA, Whitham EM. The Symbol of Modern Medicine: Why one snake is more than two. Ann Intern Med. 2003; 138:673-677.

7. Potter, Edwin S. Serpents in Symbolism, Art, and Medicine: the Babylonian caduceus and Aesculapius club. Private printing: California 1937.

8. Lederer SE, More SE, Howell JD. Medical history in the undergraduate medical curriculum. Acad Med. 1995; 70(9):770-6.

9. Angliss S. The Science Museum Book of Amazing Facts: Medicine. Hodder Books: London 1998.

10. Fiona. History and Physical. Adventures in Medical School. http://www.urbanhonking.com/medschool/archives/2006/02/the _history_and.html. 2006.

11. Gaita R. A Common Humanity: Thinking about love and truth and justice. London: Routledge, 2000.

12. Shadbolt N. Attitudes to Healthcare and Self-care Among Junior Medical officers: A preliminary report. Med J Aust 2002; 177 (1 Suppl): S19-S20.

13. Schattner P, Davidson S, Serry N. Doctors' Health and Wellbeing: Taking up the challenge in Australia. Med J Aust 2004; 181: 348-349.

14. Epstein R. Mindful Practice. JAMA 1999; 282: 833-839.

Mohammad Ahad Qayyum is a final year medical student at the Punjab Medical College in Faisalabad, Pakistan.

Ahmad Ayaz Sabri is a final year medical student at the Punjab Medical College in Faisalabad, Pakistan.

Fawad Aslam is a fresh medical graduate from the Aga Khan Medical College in Karachi, Pakistan. 